\title{
¿SE POLITIZÓ EL TIEMPO? ENSAYO SOBRE LAS BATALLAS CRONOPOLÍTICAS DEL OCTUBRE CHILENO
}

\author{
¿Did time politicize? Essay about chronopolitical battles in Chilean October
}

\section{RESUMEN}

Este ensayo propone una lectura del octubre chileno interrogando la politización del tiempo, tanto como objeto de las luchas, así como también estrategia de protesta y de contraofensiva conservadora. El objetivo consiste en comprender lo que se juega en el conflicto social, como "batallas cronopolíticas" entre temporalidades del orden (la continuidad) y temporalidades de la transformación (los gérmenes de una discontinuidad que abre otro futuro). Se argumenta que resulta imprescindible problematizar la relación actual al tiempo, en específico la aceleración de la vida y las (de) sincronizaciones sociales que implica, así como también el lugar y el sentido del futuro en el conflicto político actual. Para detenerse en las batallas cronopolíticas propias a estas movilizaciones sociales, se plantea primero el aporte del enfoque, antes de circunscribir las claves temporales de las reivindicaciones. En seguida, se analiza el conflicto social como batallas de temporalidades, a partir del concepto de momentum. Finalmente, se sintetiza la pregunta por la reapropiación social del futuro.

Palabras claves: Cronopolítico, Futuro, (De) Sincronización, Momentum, Tempo social.

\section{UNIVERSUM}

Revista de Humanidades y Ciencias Sociales

\author{
ANTOINE FAURE \\ Escuela de Periodismo, Universidad \\ de Santiago de Chile - USACH, \\ Santiago, Chile. \\ Correo electrónico: \\ antoine.faure@usach.cl \\ ORCID: 0000-0002-9140-5980 \\ ResearchGate: \\ Scholar.google: Antoine Faure \\ Academia.edu: AntoineFaure \\ Este texto forma parte de la \\ investigación FONDECYT \\ $\mathrm{N}^{\circ} 11170348$ "Historia de las \\ temporalidades periodísticas \\ chilenas (1973-2013): otra \\ dimensión política de la profesión de \\ periodista".
}

Artículo recibido el 3 de marzo, 2020. Aceptado el 4 de junio, 2020.

DOI:

Web: http://universum.utalca.cl | ISSN: 0716-498X - 0718-2376 


\begin{abstract}
This essay proposes a reading of the Chilean October by questioning the politicization of time, both as the object of the struggles, protest strategy and conservative counter-offensive. The objective is to understand what is at stake in social conflict, as "chronopolitical battles" between temporalities of order (continuity) and temporalities of transformation (the seeds of a discontinuity that opens up another future). It is argued that it is essential to problematize the current relationship to time, specifically the acceleration of life and the social (de)synchronizations that it implies, as well as the place and sense of the future in the current political conflict. In order to apprehend the chronopolitical battles inherent to these social mobilizations, the contribution of the approach is first proposed, before circumscribing the temporal keys of the demands. Next, the social conflict is analysed as battles of temporalities, based on the concept of momentum. Finally, the question of the social reappropriation of the future is summarized.
\end{abstract}

Keywords: Chronopolitics, Future, (De)Synchronization, Momentum, Social tempo

En Chile, el 18 de octubre de 2019, el futuro se abrió. En una sociedad profundamente presentista y endeudada, a nivel financiero (lo que implica de consumir el futuro en el presente) así como también con su propio pasado (el golpe de Estado de 1973 y la dictadura cívico-militar), la evasión, los gritos, las concentraciones, los cacelorazos, y los paros despertaron esperanzas, aspiraciones y promesas. Un horizonte, un futuro. Otro futuro. $\mathrm{Su}$ devenir no es para nada nítido ni cierto. Precisamente, este futuro está en juego tanto en su proyección como en los métodos para alcanzarlo. Pero, el orden y la hegemonía gestados en tiempos del «no future» (los años 1980), y en permanente transición desde 1990, han sido desafiados en su más íntima profundidad, es decir, en la ruptura con un realismo que provocaba desconfianza en el futuro al equipararlo con el riesgo del caos y la catástrofe. 
Esta dimensión me parece central. En coherencia, el objetivo de este ensayo no es explicar el evento sino comprender lo que se juega en él, como desafío para este otro futuro que se ha abierto. Quiero contribuir a la comprensión del devenir de la sociedad chilena a raíz de las movilizaciones sociales de 2019 y 2020, al interrogar el tiempo y las temporalidades del octubre chileno.

Asumiendo esta lectura, insisto incierta, se deja de lado una pregunta que obsesiona desde el 18 de octubre de 2019, para enfocar mejor una segunda pregunta que planteo en adelante. La interrogante que no me interesa aquí, consiste en explicar por qué estalló el conflicto social este mismísimo día, no antes, no después. La encontramos por ejemplo en entrevistas a Jeannette von Wolffersdorff, ex Directora de la Bolsa de Comercio de Santiago (Matamala, 2019), al cientista política Juan Pablo Luna en el programa Futuro 360 (Sichel, 2019), al cientista político francés Franck Gaudichaud (Duval, 2020). Esta difícil pregunta pierde sentido debido a los tantos escollos que proyecta en su mismo horizonte, y remiten a concepciones temporales fuertes: el momento oportuno en el que estalla los conflictos; la historia como acumulación de descontentos, y una historia determinista que haría de la crisis el desemboque natural de un trayecto preestablecido. Entre continuidad y discontinuidad, estos resguardos analíticos no agotan ni totalizan la comprensión del fenómeno. En efecto, no se ha podido comprobar que estamos frente a un claro liderazgo en esta crisis que afecta simultáneamente varias esferas sociales diferenciadas, y pareciera que "asistimos a distintas etapas en las que fluidez y autonomía se reconfigurarían" (Faure y Maillet, 2020).

Paulatinamente, la pregunta se ha transformado en un segundo interrogante. ¿Qué hace que las movilizaciones hayan durado y sigan durando? Este desplazamiento es relevante de un desafío que me parece decisivo. La discusión sobre lo que ha pasado en Chile en 2019 y 2020, se focaliza precisamente en la heterogeneidad de los actores, la ausencia de liderazgo representativo y la transformación de un movimiento social. Estos factores no explican la duración del llamado "estallido social". Resulta un caso de discronía, es decir, una situación en la que existen "dificultades o 
imposibilidades de prever, anticipar o evocar correctamente cronologías y duraciones" (Bergeret y Rolland, 2018: 120). No obstante, estas cronologías y duraciones están en juego en la discusión tanto social, como política o académica sobre el evento.

La dimensión temporal es sin duda central, y debe incluirse en la discusión. Lejos de agotar todas las comprensiones, apuesto aquí a rastrear la desincronización de las temporalidades sociales y políticas en el Chile de los 30 últimos años, y la manera en la que las movilizaciones son una importante parte de las luchas para re-sincronizar estas temporalidades. Mi argumento es el siguiente: para comprender los desafíos planteados durante el octubre chileno, resulta imprescindible problematizar la relación actual al tiempo, específicamente la aceleración de la vida y las (de)sincronizaciones sociales que implica, así como también el lugar y el sentido del futuro en el conflicto político actual. Algo no menor, puesto que remite a procesos políticos y lógicas económicas que regulan la vida de las poblaciones y los individuos.

Es una línea que ha sido muy escasamente desarrollada desde el 18 octubre de 2019, para referirse a las movilizaciones chilenas. Al revisar los numerosos libros y columnas publicadas sobre este conflicto social (sin ser totalmente exhaustivo), la perspectiva está asumida en cinco textos, sin necesariamente hacer de las temporalidades un objeto de estudio (Araujo, 2019; Campos Medina y Campos Medina, 2019; Karmy, 2019a, 2019b; Stange et al., 2019). En ese sentido, planteo un enfoque investigativo, que se nutre de otros trabajos ya iniciados y en desarrollo - particularmente los de Kathya Araujo (2019), Mauro Basaure (FONDECYT Regular 1191490) o Pedro Güell (2017) —, enfoque que me parece decisivo para problematizar la vida social y política en Chile.

Propongo aquí detenerme en las lógicas específicas de las temporalidades sociales como batallas cronopolíticas. Por "cronopolítico", sigo la pista de "la producción y la transformación colectivas de normas temporales que orientan el conjunto de la sociedad" (Gardella, 2014). Defino entonces las "batallas cronopolíticas" como la relación de fuerza entre temporalidades del orden (la continuidad) y temporalidades de la transformación (los gérmenes de 
una discontinuidad que abre otro futuro). En este sentido, me interesa aquí el tiempo como objeto de politicidad.

En efecto, el problema del tiempo y de las temporalidades se revela un componente de las estrategias y tácticas en el seno del conflicto social, tanto como objeto mismo de ciertas reivindicaciones, así como también para desacelerar las relaciones sociales y resincronizarlas ante la construcción de otro futuro. Pensar las temporalidades en las movilizaciones sociales pone luz, por un lado, sobre el cambio y la refundación de una regulación política para la sociedad chilena, insertándolo en un proceso a más largo plazo que remite por lo menos a los 40 últimos años (desde la promulgación de la agenda neoliberal y la Constitución del 80 por la dictadura cívico-militar). Por otro lado, este enfoque recuerda que el tiempo, también es un objeto de lucha que remite a la centralidad del reloj desde la modernidad política y la consolidación del capitalismo. Esta consideración tampoco es una novedad para los movimientos sociales (Thompson, 2004) y los activistas (Bonfiglioli, 2001). Pero, tiene algo específico y propio dadas las transformaciones de las sociedades actuales al ampliar el tiempo digital a todos los procesos sociales el tiempo cronoscópico, o "desplazamiento de la temporalidad cronológica del reloj por un tiempo real comprimido digitalmente" (Hassan, 2014: 5) - Estas mutaciones han generado reivindicaciones propias sobre las temporalidades, que no se pueden equiparar con luchas similares en el pasado, debido al lugar histórico del conflicto (inicios del siglo XXI), y las contraofensivas que buscan dar respuestas al problema desde las mismas coordenadas de aceleración y flexibilidad temporal cuestionadas, y aquí problematizadas.

Primero abordo el lugar del tiempo en las reivindicaciones de las movilizaciones sociales chilenas de 2019 y 2020, ya sea el problema del transporte, las desigualdades sociales, la relación al trabajo, las pensiones, el endeudamiento o el problema medioambiental. A partir de esta base, propongo, segundo, usar el concepto de momentum para analizar las luchas entre las temporalidades hegemónicas y alternativas durante el conflicto 
social. ${ }^{1}$ Llegando, tercero, a abrir las pistas de los desafíos temporales del futuro que se abrió.

\section{LAS (DE)SINCRONIZACIONES, ¿UN OBJETO DE LAS MOVILIZACIONES?}

Si bien hace falta tomar precauciones para no esencializar el problema del tiempo en las reivindicaciones de las acciones colectivas, es una clave de lectura que claramente ayuda a entender las movilizaciones de 2019 y 2020, específicamente cómo las (de)sincronizaciones generan desigualdades temporales y la desposesión del futuro planteada en introducción de este texto.

\section{DESIGUALDADES TEMPORALES}

Es imprescindible notar, para empezar, que la evasión masiva que inició el conflicto social chileno de 2019 y 2020 no solo problematiza la desigualdad económica del acceso a los transportes públicos, sino también la circulación de la población y su conectividad. El tiempo es una clave de lectura que coincide además con un objeto de protesta de época. Conecta las movilizaciones chilenas con los Chalecos amarillos franceses, por ejemplo, cuando se asume que estos se levantaron frente al alza de los precios de la gasolina, un problema tanto económico, político como temporal. Si bien esta comparación debe considerarse con mucha precaución, este es un punto revelador del lugar del tiempo en las reivindicaciones de las movilizaciones sociales contemporáneas.

Por una parte, este es un elemento decisivo para comprender las desigualdades sociales y el proceso de politización de las movilizaciones. En efecto, la movilidad es un valor cardinal de las sociedades occidentales actuales, incluida la sociedad chilena. En este sentido, que Chile haya

1 Esta propuesta conceptual podría aparecer en el título de este ensayo, pero estimo que todavía está en un estado de desarrollo demasiado embrionario en mi trabajo, para ser el centro de todo el ensayo. 
despertado después de una ola de desobediencia civil frente al alza del pasaje de Metro no solo es simbólico. La (in)movilidad geográfica en una ciudad como Santiago, "en la que la circulación está auto-restringida" (Araujo, 2019: 30), metaforiza la (in)movilidad social; es más, encarna las desigualdades entre 3 millones de usuarios y una clase alta que apenas conoce los precios de Red (ex Transantiago).

Sobre esta base, afirmo que el tiempo es central en estas movilizaciones. El uso del transporte público puede llegar a ocupar una proporción muy importante del tiempo cotidiano disponible y relegar las relaciones familiares o de ocio a horarios efímeros. Por lo menos, para los usuarios del sistema de transporte santiaguino, Red influye directamente sobre la repartición de los tiempos. En efecto, las "Encuestas Origen Destinos de Viajes" han ampliamente destacado la fuerte motorización de los barrios y las comunas de clase alta $(\mathrm{ABC} 1)$ por oposición a las comunas más pobres y periféricas. En 2012, más de 64\% de los viajes del sector sur de la capital se realizaban en transporte público. Contra $14 \%$ para el sector oriente.

El problema del tiempo de transporte en relación con el tiempo cotidiano disponible se agudiza por el uso del transporte público de parte de los afectados por los abusos y las desigualdades (lo que la encuesta llama "modo Bip"). Al analizar las dimensiones de la movilidad en el gran Santiago, los sociólogos y antropólogos Yves Jouffe, Alejandra Lazo y Diego Carvajal, agudizan el argumento: los recursos socio-económicos condicionan directamente con los tiempos de transporte, y los más pobres son los que pasan más tiempo en las micros y el metro (Jouffe, Lazo y Carvajal, 2016). Define según ellos una distribución de las posibilidades objetivas en tres constelaciones de movilidad (segregativa, agregativa, y desagregativa). Si uno suma las condiciones saturadas y deshumanizantes de viaje, mejor se entiende lo que está en juego en el problema del tiempo de transporte como objeto de lucha social.

Se visibilizan también las dificultades de ascensión social, al poner en relación, a través del transporte colectivo, las clases más altas con las clases medias y bajas. Al concentrarse en el metro, en las plazas, en la Alameda, los peajes, los bloqueos de 2019 expanden la experimentación de los obstáculos 
de la movilidad social a los otros. Consiste, además, en dificultar el aparato productivo (por lo menos en Santiago y en los puertos). Finalmente, el desplazamiento de algunas marchas hacia los barrios altos de la capital apunta a problematizar al sector productivo chileno; y, visibiliza la distancia social a través del alejamiento físico. Todos estos elementos permiten entender la movilización de los estudiantes secundarios en contra de una medida —el alza del pasaje de metro - que no tenía un impacto directo sobre sus propios tiempos cotidianos sino sobre los de familiares. El tiempo ha sido, entonces, un factor clave para articular los colectivos que han participado en las movilizaciones que, no obstante, no tienen liderazgo.

Por otra parte, los análisis se multiplican a nivel mundial para comprobar la vinculación entre el ritmo urgente de la vida con la agudización y la expansión de las desigualdades sociales, el crecimiento de las patologías psicológicas y médicas (Rosa, 2010). Por un lado, un clivaje se construyó entre hiperactivos y sobre-ocupados, en oposición a otro sector que no tiene empleo ni productividad y que corresponde, a grosso modo, al trabajo informal y ambulante. En Chile, el fenómeno se observa por ejemplo en la precarización temporal del trabajo, ya sea en el tipo y en la duración del contrato de tiempo de trabajo o "una indiferenciación de los tiempos y espacios de trabajo y de no trabajo" (Stecher y Sisto, 2019: 48). Estos autores caracterizan el fenómeno como la extensión de horas de trabajo, la flexibilización de los modos de este y de la aceleración de la producción, es decir, de la productividad al reducir la variable tiempo.

Remite a una brecha que describe con maestría Jonathan Crary (2014), que consiste precisamente en romper con los ciclos de sueño de los trabajadores precarizados y poco a poco impedir sus relaciones sociales para una economía del tiempo. Otra línea del mismo clivaje social se genera por el problema del tiempo: las asimetrías de género. Ya sea por la organización del tiempo de trabajo (cotidiano y semanal), por la duración de la vida activa, o por la articulación de las distintas temporalidades en el caso de la paridad en política, por ejemplo (domesticidades, tiempos electorales, tiempos de la acción pública y de las instituciones). 


\section{DESPOSESIÓN DEL FUTURO}

Una segunda dimensión temporal que es objeto de las reivindicaciones propias al octubre chileno vincula las desigualdades sociales con la proyección hacia el futuro. En efecto, las denuncias de los movilizados sobre las desigualdades, injusticias y los privilegios en la sociedad chilena remiten al trabajo del sociólogo Pedro Güell sobre la importancia de las perspectivas temporales para el estudio de la subjetividad, y en específico la percepción del bienestar y el malestar. Este investigador muestra, a partir de un trabajo cuantitativo, que el factor socioeconómico tiene una directa relación con las perspectivas temporales individuales, concebidas tanto contextual como socialmente. La subjetividad se construye en relación a la evaluación de la trayectoria de vida, lo que explica la interrelación entre orientación temporal y las variables sociales, económicas y demográficas (Güell et al., 2014). Para sintetizar los resultados, se observa que los grupos que muestran un mejor bienestar subjetivo, se vinculan con la percepción positiva del pasado y una orientación mediana hacia el futuro. Al contrario, una relación negativa al pasado es la variable temporal que explica, según ellos, el malestar social. Este análisis da una interesante clave temporal para comprender las reivindicaciones de los movilizados que, precisamente por medio de la acción colectiva, denunciaron un malestar formulado como una sociedad a velocidades diferenciales (entre privilegiados y subordinados).

Esta dimensión subjetiva de las perspectivas temporales conecta con una dimensión objetiva propia a las promesas y esperanzas hacia el futuro, y se opone al imaginario neoliberal de un emprendedor individualista que se realiza a corto plazo. Varios dispositivos y políticas públicas están en el cruce de estas dos dimensiones, ya sea el sistema de pensiones por capitalización, así como también el incentivo al endeudamiento como extensión del sueldo en una sociedad orientada al consumismo. La constitución del sistema de pensiones como problema público, y el cuestionamiento del individualismo y el mercado como variables de ajustes por proyectos de solidaridad intergeneracional, se han elaborado a partir de las frustraciones y la ruptura con aspiraciones (para 
el futuro biográfico de los chilenos) a jubilaciones dignas. Es una dimensión no suficientemente estudiada, a mi juicio, en los trabajos sobre " No + AFP" (Rozas y Maillet, 2018), que no consideran la dimensión política de la relación de estos movimientos sociales al futuro.

Las trabas puestas a las proyecciones a un futuro positivo también se operan en la lógica misma de endeudamiento transversal de la sociedad chilena - no obstante, resulta de lógicas y propósitos distintos según las clases sociales. Este dispositivo garantiza oportunidades, según sus promotores, y permite asumir las privatizaciones de los servicios públicos, así como también aumento del precio de la vida. Pero, se juega precisamente una desposesión del futuro, su consumo en el presente y su experiencia como préstamo y reembolso como dispositivo de control (Lazzarato, 2014). Resulta un dispositivo de subjetivación que pone en juego la idea misma de porvenir y la política entendida como proyección en el futuro y "suma a la mayor parte de la población en un presente angustioso e interminable (pues la morosidad nunca concluye) e impide que las personas puedan proyectar personal e individualmente un futuro mejor" (Stange et al., 2019: 47). Consume toda expectativa de futuro, porque el deudor está desposeído de porvenir.

Una última perspectiva fundamental para entender cómo el futuro es objeto de las movilizaciones de 2019 y 2020, reside en las articulaciones de la crisis medioambiental con las desigualdades (acceso al agua, sequía, zonas construibles, etc.). El problema ecológico es claramente un acelerador y multiplicador de los problemas que son el objeto de las movilizaciones y, desde esta perspectiva, no resulta extraño que reivindicaciones socio-ambientales se hayan articulado a las movilizaciones que se han intensificado y masificado desde el 18 de octubre, tanto en la capital como llamativamente en las regiones y los territorios llamados "zonas de sacrificio" (Allain, 2020).

En breve, en el seno mismo de las desigualdades y la injusticia denunciadas, las (de)sincronizaciones son una clave de comprensión decisiva. La imposibilidad de proyectar un futuro, tanto por razones ligadas a la amenaza de una crisis socio-ambiental, a dispositivos como el endeudamiento o al sistema de pensiones por capitalización, así como también 
los factores socioeconómicos como variables de las perspectivas temporales y de la percepción subjetiva del bienestar, son objeto de reivindicación. Los privilegios tienen también una formulación ampliamente temporal, ya sea como clave de la brecha de género, del problema del transporte público y de las mutaciones del trabajo. No me parece un azar que la propuesta de ley para reducir legalmente el tiempo laboral a 40 horas haya sido objeto de muchos debates entre expertos (López y Petersen, 2017) y a la vez, la primera medida de la agenda social aprobada en la Cámara de Diputados, el 24 de octubre de 2019. Si bien estaba ya en curso cuando surgió el conflicto chileno, el proceso legislativo ha sido acelerado y se encuentra desde el 9 de noviembre de 2019 en el Senado, donde el proceso se deceleró (¿estratégicamente? Dejo la pregunta abierta...).

El tiempo es uno de los objetos de las movilizaciones sociales y, a la vez, una clave analítica fructífera para comprender qué está en juego y los desafíos que se abren para el futuro. Sin embargo, no es suficiente para proyectar un análisis de las batallas cronopolíticas que vive la sociedad chilena. Hace falta reinsertar estas reivindicaciones en las luchas entre temporalidades conservadoras y transformadoras.

\section{EL MOMENTUM: ¿HERRAMIENTA CONCEPTUAL PARA ANALIZAR LAS BATALLAS CRONOPOLÍTICAS?}

Para abordar las batallas cronopolíticas, propongo usar el concepto de momentum. Después de plantear brevemente en qué consiste esta idea, visibilizo las iniciativas y propuestas temporales del octubre chileno, es decir, las resistencias y apropiaciones colectivas que impulsan un nuevo tempo social y político. Finalmente, el momentum del conflicto social implica considerar la reactividad, la velocidad y la inercia de la contraofensiva de las fuerzas políticas y económicas conservadoras. 


\section{EL MOMENTUM: CIRCUNSCRIPCIÓN DE UN CONCEPTO}

Tomo prestada la idea de momentum de la física mecánica anglosajona (desde Newton). Para esta, no solo define el "movimiento" (como lo dejaría entender un trabajo etimológico), sino la cantidad de movimiento como producto de la relación entre la masa de un cuerpo en movimiento y su vector de velocidad. En otras palabras, es una dinámica que explica la acción de una fuerza exterior sobre un sistema, es decir, la variación de la inercia (o momentum lineal) a partir de un impulso (debido a la posibilidad de transferir el movimiento a otro cuerpo). Un ejemplo clásico sería el de la avalancha, cuya acumulación de masa y de velocidad crea una inercia cuando enfrenta obstáculos que, a la vez, hacen variar su dinámica al frenar dicha avalancha. Se ve aquí entonces un primer aporte al uso de esta idea en el caso de los movimientos sociales y de las batallas temporales: estos actuarían como un impulso (en este caso interno a la sociedad) que hace variar la continuidad lineal de cierto orden (o la estabilidad de un sistema).

En economía, el momentum es un indicador bursátil avanzado, usado para determinar las tendencias de ciertos títulos (su dinámica en el tiempo), y dar señales de compra y venta (dicho de otro modo, evaluar el timing de la apuesta bursátil). Si bien este uso conserva la lógica de un orden temporal lineal para anticipar los cambios, agrega cierta utilidad para mi propósito, en el sentido de que suma a la acepción de la física mecánica la noción de un impulso al cambiar de posición o tomar decisiones. Si bien esta manera de plantear el momentum es demasiado racional para analizar el mundo social, más aún en el caso de movilizaciones que carecen de liderazgo y representantes, integra variables importantes para pensar las batallas cronopolíticas durante un conflicto social, al considerar el tempo de la hegemonía, es decir la velocidad relativa en el que sucede la vida social. En este caso, el ritmo de una época donde la aceleración de la vida social y la inmediatez parecen constituir preocupantes tendencias, y juegan a favor de la conservación del orden.

Para terminar con este breve apartado teórico, propongo aquí el concepto de momentum definido para un uso en Ciencias sociales y Humanidades como 
la dinámica de un tempo social sobre la que se puede actuar, por la capacidad de mantener este tempo en la duración u orientar cambios (el impulso), ya sean conservadores (en el sentido de mantener un statu quo o ajustar para que no varíe profundamente) o reformistas. ${ }^{2}$ No lo concibo como el filósofo chileno Rodrigo Karmy que lo usa en referencia al "instante de peligro" benjaminiano en el que emergen "nuevas formas de inteligibilidad del tiempo histórico". ${ }^{3}$ También es más amplio, en mi uso, que el "tiempo oportuno" aristotélico, que concibo más bien como el impulso que desvía el momentum.

Entendido de tal manera, este concepto me parece particularmente útil por dos razones, que entran en juego en las batallas cronopolíticas que me interesan. Primero, si bien implica la continuidad lineal del orden, incorpora la posibilidad de acciones para mantener control sobre esta inercia social y política. Por ejemplo, las reformas a la Constitución de 1980, que el bloque de derecha aceptó para ganar fuerza y legitimidad electoral, e in fine, mantener el momentum. Segundo, integra la influencia que emerge de las posiciones sociales y políticas de los actores, pero tampoco las cosifica de manera determinista. Deja la posibilidad de que se ejerza un cambio profundo, lo que llamé antes un impulso que desvía el movimiento lineal. Parte de la pregunta reside entonces en saber si, en el futuro, el 18 de octubre y los meses que han seguido serán reconocidos y analizados como un impulso.

Es un concepto que permite asumir la cronopolítica como conflicto, es decir, las estrategias y tácticas que impulsan dudas y contribuyen a contrarrestar el momentum de los dominantes (o, desviar y hacer variar el curso del orden). El momentum designa, en suma, una dinámica de influencia estratégica producto y objeto de las estrategias de los actores para cerrar y abrir las posibilidades y opciones políticas, sus orientaciones y su tempo a través

2 En este sentido, el concepto dialoga particularmente bien con la idea de "mecanismos de encadenamiento" desarrollado a propósito de los productos políticos de los movimientos estudiantiles chilenos. Ver Bidegain Germán y Maillet Antoine, "Social movements' influence beyond agenda-setting: cycles of protest, chaining mechanisms and policy outcomes in the Chilean student movement (2006-2018)", paper presentado en la conferencia de la Red de Economía Política de América Latina, 2019.

3 Hasta ahora, ocupamos el vocablo de «evento» para designar esta ruptura. 
de batallas cronopolíticas. Es específicamente interesante para analizar estas disputas porque privilegia por sí nociones temporales: (dis)continuidad(es), duración, inercia, prolongación, tempo, ritmo y timing.

Veamos ahora, cómo se podría aplicar en el caso del conflicto social chileno de 2019 y 2020, y específicamente en términos de batallas temporales, empezando por el aparente impulso creado por el tempo de las protestas.

\section{LA BATALLA DE TEMPO DE LAS PROTESTAS}

A través de numerosas y diversas protestas, tanto en sus objetos, reivindicaciones como en sus formas, composición y repertorios de acción, las movilizaciones sociales chilenas han implementado un conflicto sobre el tiempo que desarrolla a través de sus temporalidades. En otras palabras, los usos del tiempo en las acciones colectivas han consistido en frenar y obstaculizar la inercia del momentum chileno instalado desde la dictadura cívico-militar, y prolongado por las élites cívico-políticas propias al pacto postdictatorial. Bien se formula en el famoso eslogan "No es por 30 pesos, son 30 años", que fue extendido en "No son 30 pesos, son 500 años" por la psicóloga Manuela Badilla (2019) al momento de la destrucción de parte del patrimonio recordando la conquista española ${ }^{4}$. Estas temporalidades son el corazón de las estrategias y tácticas tanto para desacelerar las relaciones sociales como para desincronizar y resincronizarlas ante la construcción de otro futuro.

No es tampoco una táctica fundamentalmente nueva. Históricamente, los procesos revolucionarios y las crisis han intervenido los instrumentos temporales de regulación de la vida colectiva e individual, por ejemplo, el calendario, con el objetivo de prolongar las movilizaciones y disputar la inercia del momentum. La Revolución francesa ha cambiado el nombre de los meses y la duración del año republicano. Más recientemente el movimiento "Nuit debout" (2016) ha interrumpido el calendario al proclamar un mes de

4 En este caso la estatua de Pedro de Valdivia en Temuco, en pleno territorio mapuche. 
marzo sin fin, inicio de una nueva etapa revolucionaria que ha seguido la serie numérica de fechas sin nunca llegar a abril. Se decretó, en estas comunidades, el 32 de marzo, el 33, el 34, etc.

En una lógica similar, pero a partir de otras iniciativas, los movilizados chilenos han organizado y coordinado las movilizaciones según sus propios ritmos, pulsos y combinaciones. Por ejemplo, se han multiplicado las protestas cada semana, al fragmentar las concentraciones en torno a distintas reivindicaciones específicas a lo largo de los días y de la semana. Estas estrategias, si bien no parecen necesariamente concertadas y racionalizadas, han ejercido una fuerte presión sobre los actores del sistema político chileno. Tal como lo escribe el sociólogo Danilo Martuccelli, "la 'traducción' de las movilizaciones no sigue en absoluto el guión habitual; los manifestantes y los vecinos, los dos grandes rostros de la ciudadanía activa hoy en día en Chile, se toman su tiempo, se encuentran, discuten, federan demandas probablemente heterogéneas" (Martuccelli en Araujo, 2019: 438).

La disputa del momentum se juega en la misma dimensión temporal de las movilizaciones, precisamente en su tempo. Martuccelli, que también usa esta última palabra, desarrolla lo que le parece decisivo en estas batallas de temporalidades:

En todo caso [las movilizaciones] imponen el ritmo de sus pasos y de sus reuniones a los otros actores sociales. No dictan - ¿todavía? - el futuro, pero imponen desde ahora las temporalidades. La urgencia de los miembros de la élite (política, económica, intelectual) contrasta fuertemente con la lentitud asumida por los ciudadanos. No es cuestión de precipitarse; de perder la realidad de las oportunidades bajo el supuesto de ganar tiempo (Martuccelli en Araujo, 2019: 438).

A través de este tempo, concuerdo que "las movilizaciones, marchas y cabildos, toman la dirección de los eventos" (Marttuccelli en Araujo, 2019: 439), y lo analizo como una lucha por influir sobre el momentum, es decir, el control sobre el curso de las cosas, las orientaciones y el ritmo para salir de la inercia de una hegemonía que llegó a su punto de ruptura. Se trata de salir de la reacción a la acción gubernamental, enmarcada en ciertas opciones 
realistas y un imaginario presentista, para prolongar las protestas, el tiempo de las movilizaciones y la apertura del futuro.

Este tempo ofrece una primera ventaja táctica que consiste en generar una presión social continua al repartirla en el tiempo y en el espacio. Se obtiene al alternar entre las reivindicaciones, día tras día, y coordinarse de manera flexible por redes sociales. Conecta los problemas, diversifica los movilizados, presiona para hacer agenda. Se produce al programar marchas y concentraciones todos los días a la misma hora. También funciona a partir de una irregularidad propia de ciertas acciones colectivas (las performances del colectivo LASTESIS o la movilización de noche en bicicleta).

Resulta que los episodios de protesta son de duración variada. Se distribuyen también en un espacio descentralizado, tanto por focos de movilización como a lo largo del territorio (capital y regiones), entre campo y urbes. La simultaneidad de estos focos gana potencia conflictual con la imprevisibilidad de la duración, así como también de la regularidad de las protestas. Por una parte, desorganiza la regulación, el funcionamiento eficiente y el ritmo cotidiano de la ciudad. El atasco en Santiago lo ha mostrado. En general, las relaciones sociales se desordenan porque ocurren a contratiempo. Por otra parte, simultaneidad, irregularidad e imprevisibilidad dificultan el mantenimiento del orden público; y las protestas desafían los tiempos verticales del Estado y las fuerzas del orden, al prolongar los cacerolazos después del toque de queda.

Ofrece otra secunda ventaja para los movilizados, dado que este tempo de la acción colectiva consiste precisamente en mantener la presión social duradera, sin impedir que parte de la vida cotidiana siga su curso. Es imprescindible para los mismos movilizados —más aun debido a su heterogeneidad socioeconómica- que, así, no arriesgan sus recursos, trabajos o el abastecimiento. Y construye la oportunidad de conseguir los resultados esperados al prolongar la relación de fuerza en la calle. Esta lógica de acción colectiva no es nueva, cuando se observa en los 30 últimos años la multiplicación de las protestas los sábados o los domingos, como en el caso de "No + AFP", pero se intensificó y se diversificó más aún. 
A través de iniciativas sin necesaria coordinación y liderazgo, se mueven las temporalidades de la presión para luchar contra las sincronizaciones mediadas por el mercado, y las desincronizaciones sociales y políticas propias de la aceleración de la vida social. En las burbujas temporales de las protestas, se han paulatinamente incluido servicios mercantiles y solidarios: negocios informales y ambulantes de objetos útiles durante la protesta, así como de bienes de consumo (bebidas, comida, etc.); almuerzos populares, servicios de primeros auxilios o hasta barberos y peluqueros que atienden a los manifestantes gratis. No se trata acá de negar el carácter directamente político, económico o estratégico de estos "servicios", sino de poner en evidencia la lentitud que necesitan y su contribución a la fabricación de una comunidad. Se ve un ataque directo a la vida social acelerada que rige la sociedad chilena (como las sociedades occidentales en general).

Frente a la fragmentación de las quejas y de las movilizaciones, y la descentralización de los focos de protesta, el carácter articulado del movimiento social se encuentra en la apuesta a tomar el control del tiempo, para dar otro tipo de realismo a los cambios que exige y legitimar un nuevo pacto social, en ruptura con la aceleración de la vida. No obstante, no se puede pensar esta ofensiva temporal sin tomar en cuenta la contraofensiva conservadora que implica la inercia del momentum. De ahora en adelante, planteo la pregunta: ¿cómo el Estado y las élites — tanto políticas como económicas - intentaron neutralizar el impulso y tempo de las movilizaciones sociales para evitar que se prolongaran e hicieran vacilar el momentum chileno?

\section{REACTIVIDAD, VELOCIDAD E INERCIA DEL MOMENTUM}

Las movilizaciones sociales han interrumpido la linealidad de la regulación política y el crecimiento económico de la sociedad chilena disputando el momentum. Lo han hecho al poner en juego por lo menos tres dimensiones de las temporalidades: la aceleración de las relaciones sociales, la suspensión de una visión lineal del tiempo social, y la reactividad mediática como dispositivo conservador. En el cruce de estas tres dimensiones, se juega 
por una parte cómo mantener o ganar control sobre el cambio social, y, por otra parte, se problematizan nudos temporales de la sociedad y la fabricación del futuro. Esto pone en evidencia la centralidad política y social del problema de las temporalidades en la actualidad.

\section{"VA A TOMAR TIEMPO": RESISTENCIAS A LA ACELERACIÓN SOCIAL}

Uno de los estribillos, tanto en las conversaciones informales como en las declaraciones públicas, repite: "Va a tomar tiempo". Entre líneas, la salida de crisis; el cambio constitucional; y/o, la regulación del conflicto; el cambio social, es decir, un nuevo Chile en su propia cotidianeidad. Esta frase lúcida, al asumir que las demandas son amplias y las mentalidades profundamente ancladas en las relaciones sociales, revela a la vez que un horizonte de sentido se ha instalado en contra de la aceleración de la decisión política o de los mecanismos técnicos.

Transparenta también cierto miedo, bajo la forma de preocupación, incompetencia o hasta impaciencia. Incomoda, al asumir la lentitud del cambio social e institucional. Incomoda, al proyectar un futuro distinto y competitivo. Incomoda, al impedir esta capacidad de adaptación rápida y eficiente al entorno. El miedo se produce por la ruptura de este régimen de temporalidad mediado por el mercado, y que combina velocidad, presentismo y reactividad. Pero tampoco se esconde la incertidumbre de los mecanismos para re-sincronizar estas temporalidades, en una nueva combinación que reapropia mediciones, ritmos y secuencias temporales.

Como lo plantea el sociólogo australiano Robert Hassan, la aceleración de las sociedades (occidentales) en margen de la globalización y de un régimen de producción post-fordista, ha de-sincronizado las distintas temporalidades, lo que afecta la democracia, las relaciones sociales, así como las patologías personales. El sociólogo alemán Harmut Rosa encuentra en esta de-sincronización (propia a la modernidad, en sus palabras), la explicación a la constitución de un grupo oligárquico autónomo, al que la aceleración de las 
relaciones sociales y de la toma de decisión asegura un monopolio político. Las movilizaciones expresan el rechazo de esta desincronización, que ha participado de la acumulación de abusos y desigualdades, así como también de la ruptura de la economía moral de la sociedad chilena.

Finalmente, en este "Va a tomar tiempo", se revelan los márgenes de un campo de batalla en el que entra el orden tanto político como económico y social. El carácter incremental del proceso deja abiertos espacios para una lucha, no solo sobre lo que debe ser el futuro; sino también sobre cómo acceder a este: ¿cuál es el método? ¿Cuáles son las etapas? ¿Cuáles son los instrumentos adecuados y las buenas prácticas?

En todas estas preguntas, la duración del proceso ofrece posibilidades de incidencia, influencia, lobby; que remiten a rutinas y saberes acumulados por aquellos que están en una posición de dominación, en consiguiente desplegados con velocidad. Ya el camino constituyente implica distintas temporalidades que son, muy precisamente, donde se juega la captación política por parte de los profesionales de la política. Tiempos largos de negociación y preparación en los que los partidos políticos y la experticia son centrales; plebiscitos que aceleran la captación convencional de las preferencias parlamentarias y constitucionales en un mismo tiempo y según el mismo modo de votación.

\section{LA INERCIA DE TIEMPOS INSTITUCIONALES ACELERADORES}

En una lúcida columna, los sociólogos Luis Campos Medina y Fernando Campos Medina ocupan el enfoque sobre la aceleración de la vida social para llamar a más calma política, y dar el tiempo necesario a la deliberación, reducir las presiones sobre la toma de decisión, tomar el tiempo de producir una acción pública basada en un profundo y largo trabajo. La clave para transformar la conducción oligárquica de la sociedad reside en buena parte, según ellos, en la capacidad de las movilizaciones a reducir esta aceleración.

Tres elementos lo comprueban, a sus ojos. Primero, la rapidez de la agenda y las medidas sociales vacías, sin profundidad, para apagar el fuego sin 
proceso deliberativo y constituyente. Es aquí donde veo la dinámica temporal del momentum: seguir paradójicamente con el ritmo acelerado propio al orden inmovilista para no dejar espacio al cambio, ahogarlo desde la fe en el gradualismo y un aceleracionismo capitalista y conservador. Segundo, frente a esta reactividad, dichos sociólogos destacan la necesidad de tiempo que impone la negociación democrática. Tercero, abogan a un ritmo político desacelerado para ganar inclusión y legitimidad en la batalla sobre el sentido de las temporalidades y su dirección. El mejor ejemplo de este llamado a desacelerar los ritmos de la sociedad chilena reside, según los dos investigadores, en las presiones sociales para una Asamblea constituyente que activa esta lucha contra el nexo aceleración/oligarquismo al ampliar el espectro de los actores involucrados y bajar la velocidad del proceso de deliberación para llegar a una decisión constitucional.

Como acto de respuesta a este proceso de desaceleración, el "Acuerdo por la Paz y la Nueva Constitución” es, para Luis Campos y Fernando Campos, el dispositivo del "sistema político y [del] gobierno [para buscar] acelerar la disolución de las protestas que sigue planteando la necesidad de hacer las cosas 'de otro modo"'. En efecto, a través del proceso constituyente, el componente parlamentario de los partidos políticos ha intentado mostrar su reactividad y, por esta vía, quitar legitimidad a las exigencias sociales. Pero, no solo consiste en acelerar la disolución de las protestas, sino que, al asumir ciertas etapas, así como cierta urgencia, el personal político profesional produce sus propias temporalidades y guarda control sobre el cambio social, incluyendo la continuidad de su propio rol de mediación política. Un buen ejemplo reside en las incertidumbres reveladas por las negociaciones tanto en la Comisión técnica como entre partidos políticos, que paralizan el tiempo del cambio constitucional, así como también de las regulaciones sociales, entre reactividad y largo plazo. Abren el espacio a todas las estrategias y tácticas para influir sobre el proceso constituyente antes mismo de su implementación, es decir, calibrar y enmarcar sus posibles resultados.

Comparto los argumentos de esta columna publicada el 29 de noviembre de 2019, sobre la necesidad de intervenir las temporalidades del campo 
político. Sin embargo, esta intervención implica, a mi juicio, tomar en cuenta los otros dispositivos políticos que entran en competencia para el control de las temporalidades. Los cabildos auto-convocados son uno de estos dispositivos. No solo son determinantes para incidir sobre la manera de canalizar las voces, sino que implican un método que tiene su propio tempo. Apuestan a procesos lentos de conversación, concertación y canalización, internos y externos. La disputa es doble: semántica, por un lado, entre colectivos, cabildos o asambleas; y de voluntades, entre colectivos auto-convocados, municipios y Estado. Estas batallas alumbran los ritmos y las duraciones de cada proceso y etapa, y condicionan las posibilidades de cambio que se implementa por esta vía. Cada espacio político trata de tomar la ventaja en la administración de las temporalidades del proceso de concertación.

\section{REACTIVIDAD Y VELOCIDAD MEDIÁTICO-POLÍTICA}

En esta batalla, la alta velocidad de las temporalidades mediáticas actúa en respaldo de los actores dominantes y conservadores y su trabajo para mantener la dinámica del momentum frente al impulso de las movilizaciones. La propiedad de los medios de comunicación, así como el uso hegemónico de fuentes oficialistas o los panelistas e expertos a los que se le da tribuna, bien muestran la articulación entre las intenciones políticas y las plataformas mediáticas. El conflicto se sitúa en la respuesta que dan los movilizados a las temporalidades mediáticas, por la comunicación directa y los medios alternativos disponibles en línea. Múltiples sitios de noticias y de ciberperiodismo se han mostrado muy activos y se encargan de alimentar las redes sociales de voces alternativas a los profesionales de la política y los medios de comunicación masivos.

La comunicación sin mediación concurre a este fenómeno, con más o menos desempeño, al generar contratiempos y contra-espacios noticiosos que no tienen plazos regulares sino la intención de entregar contra-información e intervenir la agenda político-mediática. Los representantes públicos la usan cuando necesitan hacer declaraciones (solo hace falta recordar las disculpas 
"río abajo" de los diputados Boric y Jackson después de votar a favor de la ley anti-saqueos). Los usuarios generan sus propios contenidos durante las marchas y las acciones colectivas, Contenidos generados por ususarios (CGU) que entran en batalla en el momento de (des)credibilizar tanto al movimiento social como al gobierno. La aceleración de las comunicaciones no es, entonces, un proceso lineal y unívoco, sino que contribuye un espacio de lucha por controlar la narrativa y la legitimidad social, el momentum.

En efecto, en esta batalla entran también los ritmos mediáticos como dispositivos que refuerzan el ritmo de la contraofensiva conservadora. En un país donde la mayoría de los medios masivos pertenecen a esta reducida élite (los Edwards, Luksic, Saieh, etc.), revela la inercia de la dinámica estratégica de las élites para prolongar, mediáticamente hablando, el momentum. Con tal propósito operan la noticiabilidad, los marcos de interpretación y las relaciones rutinizadas con las fuentes hegemónicas y oficialistas. Al otorgar un lugar secundario a la evasión masiva del metro en la agenda mediática, los medios confirman la negación de su dimensión política. Coincide con la fase de criminalización de la desobediencia civil y la fuerza política desplegada por el Estado (gobierno, militares, intendentes, etc.) para mantener la dinámica del momentum.

En una segunda fase, el evento, desencadenado por la misma decisión del estado de emergencia por parte del gobierno, organizó la dinámica de cobertura $24 / 7$, en un régimen de simultaneidad (repetir las imágenes del evento en curso) y permanencia (el flujo de noticias es interrumpido y se concentra, durante diez días, sobre el estallido social). La mediatización, el evento y el actuar de los actores políticos se fusionaron para constituir una misma cosa, el "tiempo real" acelerado para una población en estado de sitio. Otra vez, una táctica político-mediática para mantener el momentum a través de un flujo continuo de noticias sobre los acontecimientos.

Periodísticamente hablando, dispositivos como la doble pantalla regulan el visionado de estos múltiples y veloces flujos. Permiten conservar la imagen que la sociedad tiene de sí misma, y hasta mantener a todo costo la morfología del campo de las posibilidades políticas. Es decir, de la legitimidad del futuro 
vigente y que está en disputa. Es funcional a la narrativa conservadora porque se inscribe en la derecha línea de la aceleración de los tiempos sociales. El flujo acelerado de noticias de múltiples orígenes satura los tiempos sociales e individuales, y ofrece coordenadas para actuar rápida y reactivamente con el fin de conservar el momentum.

La actualización es el dispositivo clave para la ofensiva políticomediática en estas batallas cronopolíticas. Asume la aceleración del tiempo social y de los micro-cambios sobre los que la continuidad del orden se asienta. Produce el presente mediático como un proceso linear y cumulativo que se puede renovar en gestos repetitivos, pero siempre distintos. Naturaliza el momentum de las oportunidades sociales, así como de las ofensivas y contra-ofensivas políticas.

Señales de este control se encuentran en las temáticas de los programas noticiosos post-estado de emergencia, que están todos orientados hacia el estallido, el nuevo pacto y el proceso constituyente. Se asume la política de los acuerdos, y se re-institucionaliza, mediáticamente hablando, el tiempo de la negociación por sobre las temporalidades del cambio. Los canales de televisión apenas muestran imágenes en vivo de las acciones colectivas, ya sean marchas o performances. Ya no son eventos, sino que retoman su lugar clásico de noticia segundaria en una pauta.

\section{¿OTRO FUTURO U OTRO AQUÍ Y AHORA?}

Las movilizaciones disputan en sí el futuro, como un horizonte colectivo. El octubre chileno es un imaginario político, que proyecta deseos colectivos y reapropiaciones del pasado, y problematiza el presente con su discurso hegemónico sobre la Historia. Se compite, se batalla frente a los intentos de institucionalización. El futuro es sujeto de vitalidad: se coordina, se experimenta, se vive. Este imaginario tampoco remite necesariamente a una visión teleológica, como si fuera una vuelta a la primera parte del siglo XX. También podría profundizar sentidos escatológicos propios al presentismo, es decir, el futuro como catástrofe. El escenario sigue abierto. 
A la vez, no puedo concluir que las batallas cronopolíticas se hayan disputado sobre concepciones concretas de futuros alternativos. Si bien se ha tratado de salir de un presente, los elementos empíricos que abordé en este texto muestran una clara batalla por los ritmos sociales, una sensibilidad para reapropiarse un aquí y ahora, más que una estrategia a mediano o largo plazo con instrumentos adecuados a este objetivo. Las batallas por el futuro serían, en este sentido, el ángulo muerto del octubre chileno.

No quita que el estado de excepción intentó y fracasó en congelar el tiempo histórico bajo la promesa de un futuro seguro y estable, una vuelta al orden temporal y social. Todo pareció acelerarse en un conflicto tempestuoso, que cristaliza reivindicaciones heterogéneas. Las relaciones sociales tensaron el conflicto, al cuestionar las asimetrías objetivas de las relaciones sociales (las desigualdades y los privilegios que iban por sí, hasta el 18 de octubre de 2019).

La batalla cronopolítica ha aparecido como el lugar de una vida colectiva, y la experiencia de la igualdad. La cena común en Plaza Dignidad, para el año nuevo, probablemente es lo más emblemático de estos anhelos de colectividad. Todos estos gestos y estas actitudes marcan un deseo de entreayuda frente a la transversal puesta en competencia de la sociedad neoliberal del yo. Son experiencias de igualdad fundamentales en la proyección de otro aquí y ahora.

Los territorios son el lugar de invención de nuevas sociabilidades donde se actúa una reciprocidad, que obviamente no está institucionalizada y que, por lo mismo, disputa cierto conservadurismo. La escala local se ha vuelto, de manera incipiente, el lugar de destrucción y construcción del orden social. No es una casualidad que la asamblea de alcaldes haya intentado tomar un protagonismo central durante el estado de sitio y a orillas del proceso de consulta nacional, y se haya reactivado para pedir una cuarentena total frente al riesgo de contagio del coronavirus. El personal político rápidamente vio que podría reorganizar un espacio desde donde trasvasar el cambio en ajustes y reapropiaciones. La nacionalización de las respuestas, desde el "Acuerdo por la Paz y la Nueva Constitución" hacia la agenda social del gobierno de Sebastián Piñera, muestra también el recelo conservador que se expresa en 
contra de la escala local, la politización sin intermediarios y el cambio social.

Las proyecciones se formulan también por una transmisión entre generaciones. Estos mecanismos van en los dos sentidos. Observé en las marchas numerosas pancartas refiriéndose a los padres, los que no tuvieron salud, los que tuvieron miedo, los que no pudieron contar con beneficios sociales. Al revés en las conversaciones informales, en las pancartas y en los testimonios, surge la preocupación social hacia los hijos y las nuevas generaciones. Por los que vienen.

Cuando las democracias se han pensado, desde hace 40 años, como un fin en sí, insuperable, la agudización de las desigualdades, la radicalización de las élites para defender el proyecto presentista neoliberal, así como también las prácticas autoritarias cada día más frecuentes, recuerdan la necesidad de proyectar un futuro con un imaginario político anti-técnico y donde el pueblo y el personal político tengan otro lugar. La vida colectiva que se ha consolidado en despertar chileno muestra la fuerza de un movimiento que pretende volver a pensar nuestras maneras de vivir en común y los ritmos desincronizados, en los territorios, en las escuelas, en los barrios, en los hogares familiares.

Para rematar sobre la idea central, la de temporalidades en la batalla cronopolítica por el momentum, este proyecto obliga a considerar que el tiempo es cada día más corto, frente a la crisis socioambiental que, por el contrario, se acelera. Impone una lucha en el mismo campo científico y en su capacidad a incidir sobre las decisiones políticas, tal como la economía y la ingeniería han tenido influencia sobre la idea misma de futuro, a través de actividades de prospección. Obliga a pensar los regímenes de historicidad, la relación entre pasado, presente y futuro.

A mi juicio, hace falta pensar el presente desde el futuro, y ya no desde un pasado hecho patrimonio. Más aun cuando el futuro no aparece de manera tan nítida en las batallas cronopolíticas chilenas, como yo lo intuía al inicio de este texto. Más bien ponen en disputa el sentido político del tiempo y la continuidad de un orden temporal presentista. Pero es precisamente en este intersticio que se abrió el futuro, cuando las movilizaciones han rechazado el porvenir como variable de ajuste del presente, y reivindican la politización del 
tiempo. La propia potencia del futuro.

\section{REFERENCIAS}

Allain, M. (2020). "Chile, the Social Crisis is Also an Environmental One", Noria Research, 18 de febrero de 2020, URL: https://bit.ly/2XdgwRN. Araujo, K. (ed.) (2019). Hilos tensados. Para leer el octubre chileno. Santiago de Chile: Editorial USACH, col. “ideas”.

Badilla Rajevic, M. (2019). "Ahí va Pedro. Chao Pedro. Que te vaya bien. No son 30 pesos, son 500 años". URL: https://bit.ly/33hV3e4.

Basaure, M. (2019-2023). "Desigualdad temporal, reproducción y exclusión social”, FONDECYT Regular 1191490.

Bergeret, A., y Rolland, J. "La construction politique en territoire frontalier: maîtrise progressive d'une dyschronie" in Marrel, Guillaume y Payre, Renaud (eds.) (2018). Temporalité(s) politiques: le temps dans l'action politique collective, Paris: De Boeck Supérieur. 2018: 119-134.

Bidegain, G., y Maillet, A. "Social movements' influence beyond agendasetting: cycles of protest, chaining mechanisms and policy outcomes in the Chilean student movement (2006-2018)", paper presentado en la conferencia de la Red de Economía Política de América Latina, 2019.

Bonfiglioli, S. (2001). "La politique du temps urbain en Italie", in CERTU (ed.), Les temps de la ville et les modes de vie, Lyon, 2001.

Campos Medina, L., y Campos Medina, F. (2019). "Estallido social como oposición a la oligarquización de la política", DiarioUChile, 26 de noviembre de 2019. URL: https://bit.ly/3hQdKd4.

Comisión Bravo (2015). Resumen ejecutivo Comisión Asesora Presidencial sobre el Sistema de Pensiones. Gobierno de Chile: Santiago.

Crary, J. (2014). 24/7: le capitalisme à l'assaut du sommeil. Paris: La Découverte, "Zones". 
Duval, J. (2020). "Franck Gaudichaud: Regardons le Chili pour comprendre dans quel monde on veut nous faire vivre", Rapports de force. L'info pour les mouvements sociaux, 11 mars 2020. URL: https://bit. ly/2D98Xok.

Faure, A., y Maillet, A. (2020). "Chile Despertó. Mobilisations sociales et politisation au Chili », Revue IdeAs, Dossier « Chile Despertó...Y después ? »(coord.: Damien Larrouqué), 15, mis en ligne le 1 mars 2020, URL: https://bit.ly/3i1OX5Z.

Gardella, E. (2014). "L'urgence comme chronopolitique", Temporalités [En ligne], 19, mis en ligne le 30 juin 2014. DOI: https://bit.ly/2PcgkOi.

Güell Villanueva, P., y Yopo Díaz, M. (2017). "Las Perspectivas temporales de los chilenos: un estudio empírico sobre la dimensión subjetiva del tiempo", Universum, 32(1), 121-135.

Güell Villanueva, P., Orchard, M., Yopo, M., Jiménez-Molina, A. (2015). "Time Perspectives and Well Being in Chile", Soc Indic Res, 123, 127145.

Hassan, R. (2014). The Chronoscopic Society. Globalization, Time and Knowledge in the Network Economy, New York: Peter Lang Publishing, "Digital Forms".

Jouffe, Y., Lazo, A. y Carvajal, D. "Néolibéralisme en mouvement. Les constellations de mobilité à Santiago du Chili”. En: Chili actuel: gouverner et résister dans une société néolibérale, A. Faure, F. Gaudichaud, M. C. Godoy H., F. Miranda P. y R. Jara Reyes (Eds.), Paris: L'Harmattan, "Recherches Amériques Latines", 133-156.

Karmy Bolton, R. (2019a) "El punto cero de la política", El Desconcierto, 20 de octubre de 2019. URL: https://bit.ly/2XiJcJ6. (2019b) "Lo que una Revuelta Des-arma", El Desconcierto, 30 de octubre de 2019. URL: https://bit.ly/39P3ZZD.

López, R. E. y Petersen, J. (2017). "El proyecto de las 40 horas y los efectos de reducir la jornada laboral en Chile", Ciper Chile, "Opinión", 11 de mayo de 2017. URL: https://bit.ly/2Xzmo8f. 
Martuccelli, D. (2019). "El largo octubre chileno. Bitácora sociológica". En: Hilos tensados. Para leer el octubre chileno, K. Araujo (ed.), Santiago

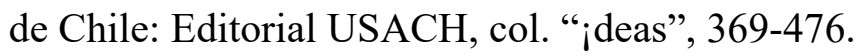

Matamala, D. (2019). "Jeannette von Wolffersdorff: La élite económica política ha naturalizado la desigualdad en Chile", $C N N$, "Nuevo Pacto", 30 de octubre de 2019. URL: https://bit.ly/316B7s0.

Rosa, H. (2016). Alienación y aceleración. Hacia una teoría crítica de la temporalidad en la modernidad tardía. Santiago de Chile: Katz Ediciones, "Discusiones".

Rozas, J., y Maillet, A. (2018). "Entre marchas, plebiscitos e iniciativas de ley: innovación en el repertorio de estrategias del movimiento No Más AFP en Chile (2014-2018)", Izquierdas, 48, 1-21.

Sichel, H. (2019). "Juan Pablo Luna: La ciencia política tiene que volver al terreno, volver a conectar con lógicas menos elitistas", $C N N$, "Futuro 360", 13 de noviembre de 2019. URL: https://bit.ly/2D0MUjO.

Stecher, A., y Sisto, V. (2019). “Trabajo y precarización laboral en el Chile neoliberal. Apuntes para comprender el estallido social de octubre 2019”. En: Hilos tensados. Para leer el octubre chileno, K. Araujo (ed.), Santiago de Chile: Editorial USACH, col. “ideas”, 37-82.

Thompson, E. P. (2004). Temps, discipline de travail et capitalisme industriel. Paris: La Fabrique, 2004.

Universidad Alberto Hurtado, Observatorio social (2012), Actualización y recolección de información del sistema de transporte urbano, IX Etapa: Encuesta Origen Destino Santiago 2012. Encuesta origen destino de viajes 2012. Santiago de Chile: Subsecretaria de Transporte. 